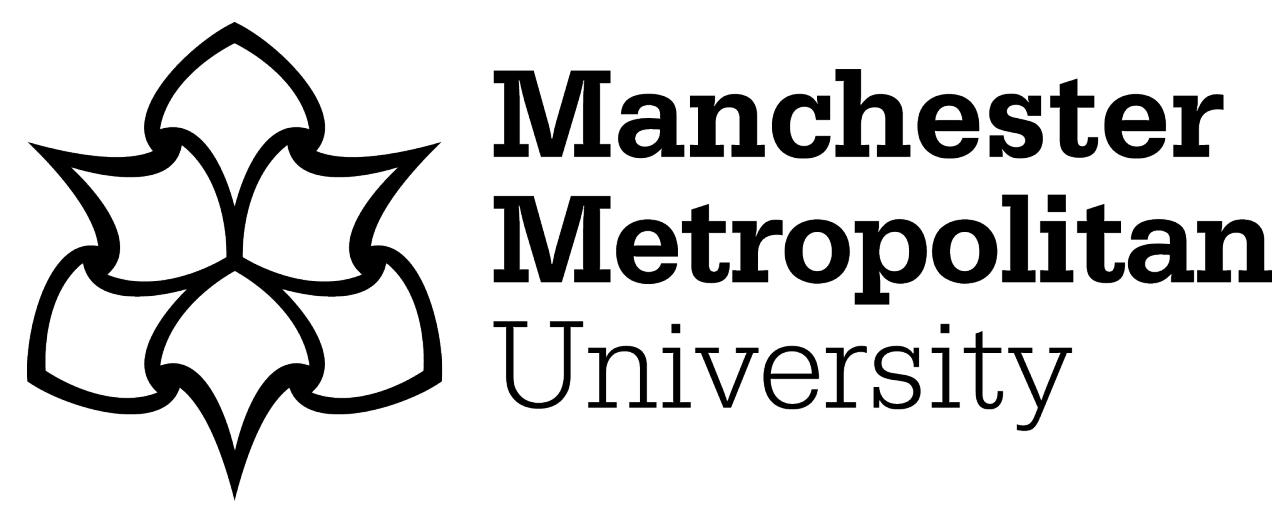

Parker, A, Powell, D and Dagnall, N (2018) Effects of Saccade Induced Retrieval Enhancement on conceptual and perceptual tests of explicit \& implicit memory. Brain and Cognition, 121. pp. 1-10. ISSN 0278-2626

Downloaded from: https://e-space.mmu.ac.uk/619615/

Version: Accepted Version

Publisher: Elsevier

DOI: https://doi.org/10.1016/j.bandc.2017.12.002

Please cite the published version 
Running Head: SIRE EFFECTS ON TESTS OF CONCEPTUAL AND PERCEPTUAL

EXPLICIT AND IMPLICIT MEMORY

\title{
Effects of Saccade Induced Retrieval Enhancement on Conceptual and Perceptual Tests of Explicit \& Implicit Memory.
}

\author{
Andrew Parker* Daniel Powell \& Neil Dagnall \\ Manchester Metropolitan University \\ Department of Psychology \\ 53 Bonsall Street \\ Manchester \\ M15 6GX \\ United Kingdom
}

* To whom correspondence should be addressed

Note: This is the final version of the authors copy. Subtle difference may exist between this and the final published version in Brain \& Cognition.

e-mail: a.parker@mmu.ac.uk

Telephone: 01612472586 


\begin{abstract}
The effects of saccadic horizontal (bilateral) eye movements upon tests of both conceptual and perceptual forms of explicit and implicit memory were investigated. Participants studied a list of words and were then assigned to one of four test conditions: conceptual explicit, conceptual implicit, perceptual explicit, or perceptual implicit. Conceptual tests comprised category labels with either explicit instructions to recall corresponding examples from the study phase (category-cued recall), or implicit instructions to generate any corresponding examples that spontaneously came to mind (category-exemplar generation). Perceptual tests comprised of word-fragments with either explicit instructions to complete these with study items (word-fragment-cued recall), or implicit instructions to complete each fragment with the first word that simply 'popped to mind' (word-fragment completion). Just prior to retrieval, participants were required to engage in 30 s of bilateral vs. no eye movements. Results revealed that saccadic horizontal eye movements enhanced performance in only the conceptual explicit condition, indicating that Saccade-Induced Retrieval Enhancement is a joint function of conceptual and explicit retrieval mechanisms. Findings are discussed from both a cognitive and neuropsychological perspective, in terms of their potential functional and neural underpinnings.
\end{abstract}

\title{
Keywords
}

Eye movements

Explicit vs. implicit memory

Conceptual vs. perceptual memory

Transfer appropriate processing 
Saccade Induced Retrieval Enhancement on Conceptual and Perceptual Retrieval Using Matched Tests of Explicit \& Implicit Memory.

\subsection{Overview and scope of research}

Recent experimental work has demonstrated that performing a sequence of goal directed horizontal saccades to a visual moving target can enhance performance on tests of particular forms of memory. The current experiment is concerned with the effects of such eye movements on different forms of memory tests that were designed to assess both explicit vs. implicit memory and conceptual vs. perceptual memory. Prior to discussing findings pertaining to eye-movement effects, the differences between types of memory (and memory tests) are outlined from the perspective of the explicit-implicit distinction and from the viewpoint of Transfer Appropriate Processing (TAP). Research indicates the theoretical and empirical value of both of these classifications (e.g., Gong et al., 2015; Mulligan \& Besken, 2013), and they provide a framework for considering the effects of eye movements on retrieval.

\subsection{Explicit vs. implicit memory}

Explicit memory requires the intentional or voluntary retrieval of information and is typically accompanied by conscious awareness. It is measured by tasks such as recall and recognition that require test responses based on information recovered from a particular study experience or episode. In contrast, implicit memory refers to a form of retrieval that is unintentional or involuntary, in which conscious awareness about some past episode, and retrieval from that episode, are not required in order to respond. Memory is inferred by enhanced performance for studied compared to non-studied stimuli; a phenomenon called priming. For example, reading words can facilitate the subsequent perceptual identification of those words relative to non-studied words. Operationally, explicit and implicit memory tests 
differ by reference to retrieval instructions and have often been referred to as intentional and incidental tests respectively (e.g. Jacoby, 1984; Richardson-Klavehn, Gardiner, \& Java, 1994, 1996; Roediger \& McDermott, 1993).

The distinction between explicit and implicit memory receives support from a range of findings using different approaches. For example, explicit memory is found to be relatively more impaired compared to implicit memory as a function of selective medial temporal lobe damage, (Corkin, 2002; Daum, Channon, \& Canavar, 1989; Glisky \& Schacter, 1987, 1988, 1989; Glisky, Schacter, \& Tulving, 1986; Graph, Squire, \& Mandler, 1984; Scoville \& Milner, 1957; Squire \& Frambach, 1990; Weiskrantz \& Warrington, 1979), schizophrenia (Danion, Meulemans, \& Kauffmann-Muller, 2001), and ageing (e.g. Wiggs, Weisberg, \& Martin, 2006).

Neuroimaging research has also detected differences in the activity of neural populations between these two forms of memory. For example, medial-temporal and prefrontal regions showing pronounced activity during explicit tasks (e.g., Donaldson, Wheeler \& Petersen, 2010; Rugg \& Yonelinas, 2003; Schott et al., 2013) and activity reductions in a range of cortical regions while performing particular types of implicit tasks (e.g., Badgaiyan, 2000; Henson, 2003; Ward, Chun, \& Khul, 2013). Experimental variables have also been found to dissociate explicit from implicit memory, with some influencing explicit but not implicit memory (Graf, Mandler \& Haden, 1982; Jacoby \& Dallas, 1981) with other manipulations producing the reverse effect (Hayman \& Rickards, 1995; Roediger, Weldon, Stadler, \& Reigler, 1992) or crossed dissociations (Java, 1994; Mulligan, 2012). The dissociations observed between explicit and implicit have been used to argue for a distinction between cognitive or neural systems hypothesised to underpin performance on these tasks (Sherry \& Schacter, 1987; Squire, 2009; Squire \& Dede, 2015; Tulving \& Schacter, 1990). This systems based approach has aligned explicit memory with a memory system dependent 
upon the integrity of the medial temporal lobes and is referred to as declarative memory. Implicit memory, in this context, is aligned with non-declarative memory, the functioning of which is attributed to a more widespread range of cortical and sub-cortical structures depending on the particular nature of the implicit task (e.g., Cabeza \& Moscovitch, 2013; Schacter \& Tulving, 1994; Squire 2004).

\subsection{A challenge to the explicit-implicit distinction: The role of transfer-appropriate processing}

An alternative framework for explaining explicit-implicit dissociations is based on the concept of Transfer-Appropriate Processing (TAP). According to this framework, the most important factor in explaining these dissociations is the overlap between the type of processing during encoding and retrieval (e.g., Roediger, 1990; Roediger, Weldon, \& Challis, 1989; Weldon, Roediger, Beitel, \& Johnston, 1995). In particular, memory is a function of the extent to which processes occurring during retrieval recapitulate those that occurred during encoding. Within this, a distinction has been made between conceptual (meaningbased) and perceptual (physical feature-based) processing (Jacoby, 1983; Roediger, 1990; Roediger, Weldon, \& Challis, 1989; Weldon, et al., 1995) ${ }^{1}$.

This framework proposes that conceptual tests are influenced by the overlap in conceptual or semantic processing between study and test (e.g., Hamann, 1990; McBride \& Shoudel, 2003; Ramponi, Richardson-Klavehn, \& Gardiner, 2007; Srinivas \& Roediger, 1990). Conversely, other tests are perceptual and are influenced by the overlap in surface or perceptual features between study and test (e.g., Blum \& Yonelinas, 2001; Craik, Moscovitch, \& McDowd, 1994; Roediger, Weldon, Stadler, \& Riegler, 1992). For example, tests of conceptual memory provide test cues that are meaningfully related to the to-beretrieved material (e.g., category labels), or are influenced by conceptual encoding processes. 
Typical examples of conceptual memory include free recall, recognition, and categoryexemplar generation. In contrast, tests of perceptual memory often use fragmented perceptual test cues (e.g., word or picture-fragments) or are influenced by changes in perceptual features between study and test (e.g., item-modality). Examples of perceptual tests include word and picture fragment completion, perceptual identification and word-stem completion.

The TAP framework provides a challenge to the systems account of explicit-implicit memory by suggesting that dissociations that have typically been observed between these forms of memory are due to confounding retrieval orientation with the type of processing required by the memory test. In particular, explicit tests are typically conceptual in nature (e.g. recall and recognition), while implicit tests are perceptual (e.g. word-fragmentcompletion and word-stem-completion). Support for this idea came from Blaxton (1989), who examined performance on both explicit and implicit tests of memory in which the conceptual/perceptual processing demands were equated, and reported that retrieval orientation (explicit-implicit) was largely redundant. In addition, neuroimaging research indicates that when conceptual and perceptual processing demands are carefully controlled, explicit and implicit forms of memory retrieval may rely on common neural mechanisms (Cabeza \& Mocovitch, 2013; Dew \& Cabeza, 2011). Consequently, according to TAP, mnemonic performance is determined largely by the match/mismatch of conceptual/perceptual processing between study and test.

However, other reports indicate that explicit and implicit tests dissociate even when processing demands are equated (e.g. Cabeza, 1994; Gabrieli et al., 1999; Graf, Squire \& Mandler, 1984; Mulligan, 1998, 2012; Parker, Dagnall, \& Munley, 2012; Tenpenny \& Shoben, 1992; Vaidya et al., 1997). Furthermore, evidence from event-related potentials (ERPs) and fMRI reveal that explicit and implicit forms of memory do derive from distinct neural mechanisms (e.g., Buckner et al., 1995; Hou et al., 2013; Schott et al., 2013; Voss, 
Federmeier, \& Paller, 2012; Ward, et al., 2013). Accordingly, there is a need to distinguish between both (i) explicit and implicit memory, and (ii) conceptual and perceptual processing. The present research takes both of these distinctions into account in relation to the effects of saccadic eye movements on memory.

\subsection{SIRE effects: principal findings and explanations}

Over the past decade, a number of research reports have shown that saccadic horizontal eye movements enhance memory accuracy. Referred to as Saccade Induced Retrieval Enhancement (SIRE) effects (Lyle \& Martin, 2010) these findings have typically been found on tests of explicit (episodic) memory. For example, in one of the first published studies, Christman, et al., (2003) found that $30 \mathrm{~s}$ of saccadic horizontal eye movements (induced by following a dot flashing from side-to-side on a screen) improved recognition accuracy for earlier presented words. Later research has replicated this effect and extended it to various forms of explicit memory, including: the recall of one's earliest childhood memories (Christman, Propper, \& Brown, 2006), associative and contextual information (Parker, Relph, \& Dagnall, 2008), landmark shape and location information (Brunye, Mahoney, Augustyn, \& Taylor, 2009), true memory in children (Parker \& Dagnall, 2012), visual scenes (Lyle \& Jacobs, 2010; Parker, Buckley, \& Dagnall, 2009), core components of autobiographical memory (Parker \& Dagnall, 2010), episodic autobiographical memory fluency (Parker, Parkin, \& Dagnall, 2013), specificity of episodic cognition (Parker, Parkin, \& Dagnall, 2017), face memory (Lyle \& Orsborn, 2011), the recall of neutral and emotive words (Nieuwenhuis et al., 2013; Phaf, 2017; Samara et al., 2011), and the reduction of both false recall and recognition of non-presented word associates (Christman, Propper, \& Dion, 2004; Lyle, Logan, \& Roediger, 2008; Parker \& Dagnall, 2007). However, a recent paper did not find evidence that eye movements could increase memory on a test of free recall (Matzke, 
et al., 2015). Considered amidst the background of positive findings, this result was surprising. Reasons for the null finding could include factors such as chance effects (false negative) or the overestimation generalisability of the effect in previous work. A more recent report that did find SIRE effects suggests that there are likely to be a number of factors that limit the generality of the influences of eye-movements on memory (Phaf, 2017), and that research should attempt to assess these factors from a theory driven perspective (Phaf, 2016). Consequently, SIRE effects may not always be observed and are limited to particular tests conditions or retrieval strategies. The experiment presented in this report shows also that eye movement effects are not ubiquitous and are therefore not found in all tests of memory.

Assuming that SIRE effects can be found under appropriate experimental conditions, then the question of the explanation of these findings arises. The original account by Christman et al. (2003) suggested the reason to be due to a hypothesised increase in hemispheric communication generated by saccadic horizontal eye movements. This explanation is based on early neuroimaging research that indicates a relative functional specialisation between the left and right prefrontal regions in explicit memory processing. In particular, the findings that suggest a role for the left prefrontal region during explicit memory encoding, and the right prefrontal region during explicit memory retrieval. This has been referred to as the Hemispheric Encoding and Retrieval Asymmetry (HERA) model. In neuroscience work, this asymmetry has been observed using both positron emission tomography (PET) (Nyberg, Cabeza, \& Tulving, 1996; Tulving, Kapur, Craik, Markowitsch, \& Houle, 1994), and more recent techniques including: functional magnetic resonance imaging (fMRI), high resolution EEG, and repetitive transcranial magnetic stimulation (e.g., Babiloni et al., 2006; Gagnon, Blanchet, Grondin, \& Schneider, 2010; Habib, Nyberg, \& Tulving, 2003; Rossi et al., 2006, 2011). 
The prediction of the HERA model is that accurate explicit memory is a function of the interaction between right hemisphere based retrieval processes operating upon the products of left hemisphere based encoding processes (Christman et al., 2006; Christman \& Propper, 2010). In this context, it is hypothesised that repeated horizontal saccades temporarily bring about the simultaneous and equalised activation of the left and right hemispheres, which provides the basis for enhanced functional coupling between the hemispheres and allowing right hemisphere based retrieval mechanisms to operate more effectively on memory traces encoded in the left hemisphere (Christman et al., 2006). Additional support for the importance of bihemispheric activity in explicit memory has been provided by Nieuwenhuis et al. (2013), who report that along with the visuomotor system, alternating right to left stimulation of the somatosensery system (vs. the auditory system) produces similarly beneficial effects for explicit memory retrieval. It was suggested that this is due to the fact that both the visuomotor and somatosensory systems (vs. the auditory system) have a stricter contralateral organisation.

However, a particular problem for the hemispheric interaction account is that direct measurements of neural activity following horizontal saccades have not yielded strong confirmatory evidence. For example, Propper, Pierce, Geisler, Christman, and Bellorado, (2007), found only partial support using the measurement of EEG coherence as an indicator of hemispheric communication. It was found that bilateral saccades (vs. no eye-movements), actually decreased coherence in the Gamma band frontal regions. In a later experiment, Samara et al., (2011) found no coherence changes in any EEG band after bilateral saccades. More recently, Yaggie et al., (2015) found bilateral saccades to bring about a numerical increase in Beta coherence across frontal regions. However, this did not achieve conventional levels of significance (reported at $p=.061$ ). The authors interpret their findings as being consistent with Propper, et al., (2007) and Samara et al., (2011). However, they also note that 
the trend towards a significant increase in coherence could be taken as suggestive of an effect. Correctly of course they are cautious in their interpretation and further research is required to substantiate this claim.

An alternative account of SIRE effects is based on the role of top-down processing (Lyle \& Edlin, 2015). This explanation is based on findings that interactions between the dorsal frontal and dorsal parietal cortex support the implementation of top-down control in both attention (Corbetta \& Shulman, 2002) and memory (Cabeza, 2008).

In relation to memory, Cabeza (2008) argues that the dorsal parietal cortex is important in explicit memory retrieval because of its function in apportioning attentional resources in accord with top-down signals from the dorsal pre-frontal cortex. The parietal cortex itself has been shown to be activated in a variety of explicit memory tasks (e.g., Ciaramelli, Grady, \& Moscovitch, 2008; Wagner, Shannon, Kahn, \& Buckner, 2005). According to Corbetta and Shulman, the top-down signal begins in the frontal-eye fields and activates more posterior regions that include the parietal and visual regions which play a role in top down attention. Lyle and Edlin (2015), argue SIRE effects arise from the influence of saccadic eye movements on a frontoparietal network of attentional control regions. In particular, eye movements just prior to episodic retrieval pre-activate this network and potentiates the contribution of this attentional network to retrieval. This serves to make stored mnemonic traces more accessible to explicit retrieval.

\subsection{SIRE effects and the explicit-implicit distinction}

To date, however, there has been little work examining SIRE effects on explicit and implicit tests. An exception is the first published report of these eye-movement effects; Christman et al. (2003) found that horizontal saccades enhanced the explicit test of recognition memory, but not the implicit test of word-fragment completion. However, this 
comparison involved tests that differed not only in retrieval instruction (explicit vs. implicit) but also in their processing requirements. Thus the tests differed not only in the requirement to retrieve previous studied items (explicit) or generate responses without such regard (implicit), but also in the type of processing needed for successful performance on each test (conceptual vs. perceptual respectively).

According to the TAP framework, recognition memory relies, in part, upon conceptual processing (e.g., Roediger, 1990; Roediger, Weldon, \& Challis, 1989; Weldon, et al., 1995). In contrast, the implicit test of word-fragment completion has been previously shown to be dependent upon perceptual processing (e.g., Roediger \& Blaxton, 1987; Roediger \& Geraci, 2005). Consequently, the reported dissociation may have arisen because of the different processing requirements (conceptual vs. perceptual) of these tests as opposed to their explicit/implicit retrieval demands. The aim of the current experiment is to assess SIRE effects on tests of both explicit and implicit memory, in which both conceptual and perceptual processing demands are equated.

To achieve this, it is important to construct an experimental situation in which (i) retrieval orientation (explicit vs. implicit) and (ii) processing demands (conceptual vs. perceptual; as determined by TAP) are manipulated orthogonally. In accord with the first criterion, it is important to ensure that the tests differ only by reference to retrieval orientation. This approach is in line with the test dissociation approach making use of the retrieval intentionality criterion (Schacter, Bowers, \& Booker, 1989). The test dissociation approach refers to the procedure used to distinguish between different types of memory using different memory tests. Experimentally, this would amount to finding an effect of a particular variable upon one test of memory, with no (or opposite) effects upon another memory test. In relation to the explicit-implicit memory distinction, this approach would require different memory tests (explicit vs. implicit) making use of the same type of retrieval cue under 
explicit (vs. implicit) retrieval orientations. If the cues are similar for each of the tests, then appropriate inferences can be made regarding the role of retrieval processes on those tests. However, if the cues differ between the tests, then it is uncertain whether any observed difference could be attributed to retrieval orientation (explicit-implicit) or the retrieval cue. This is the case in the Christman et al (2003), experiment where the implicit test used fragmented words whilst the explicit test made use of complete words. Consequently, the tests differed not only in terms of retrieval orientation, but also in terms of retrieval support.

In relation to the second criterion, it is important that in assessing the conceptual (vs perceptual) distinction the tests differ in an according manner. For example, conceptual tests should be responsive to semantic manipulations whilst perceptual tests should show dependence on, for example, study-test changes in surface and modality features (Blum \& Yonelinas, 2001; Craik, Moscovitch \& McDowd, 1994; Hamann, 1990; Jacoby \& Dallas, 1981; Roediger, Weldon, Stadler \& Riegler, 1992; Srinivas \& Roediger, 1990). In the Christman et al. experiment, the tests differed not only in terms of retrieval orientation, but in relation to their comparative requirements for conceptual or perceptual processing.

Consequently, an effective framework for assessing SIRE effects should incorporate tests that are both explicit (vs. implicit) and conceptual (vs. perceptual). This can be achieved by the comparison of explicit and implicit conceptual tests with explicit and implicit perceptual tests. In this context, the explicit and implicit tests comprise identical retrieval cues and thus require the same processing demands (conceptual or perceptual), but differ only in terms of test instructions (intentional or incidental).

\subsection{The current experiment}

Based on above perspective, the current experiment adopts a matched-test approach (the use of identical retrieval cues) with the aim of assessing SIRE effects as a function of: (i) 
explicit (vs. implicit) memory, and/or (ii) conceptual (vs. perceptual) processing demands. To reiterate, explicit and implicit tests typically differ in terms of explicit (intentional) or implicit (incidental) test instructions ${ }^{2}$. In contrast, conceptual memory tests rely on the overlap in conceptual or semantic processing between study and test, whereas perceptual memory tests are influenced by the overlap in surface or perceptual features between study and test.

In the present experiment, participants were initially exposed to a set of words from various categories. Following this, they engaged in $30 \mathrm{~s}$ of saccadic horizontal vs. no eye movements and were assigned randomly to one of four test conditions: conceptual explicit, conceptual implicit, perceptual explicit, and perceptual implicit. Those taking the conceptual explicit memory test were provided with category labels corresponding to previously studied (and unstudied) stimuli and asked to recall as many of the previously studied corresponding examples as possible (category-cued recall). Those given the conceptual implicit test were provided with identical retrieval cues and instead asked to respond to the category labels with the first corresponding examples that simply 'popped to mind' (category-exemplar generation). Participants in the perceptual explicit memory test were given word-fragments of both studied and unstudied stimuli and asked to use these cues as an aid to recalling and completing those fragments which correspond to previously studied stimuli (word-fragmentcued recall). Again, in the perceptual implicit condition, participants were given the same retrieval cues (word-fragments), but asked to complete them with the first word that 'popped to mind', rather than attempting to intentionally recall from the study phase (word-fragment completion) (see Roediger \& Amir, 2005; Roediger \& Geraci, 2005 for a review of these, and similar tests).

If the framework proposed by Christman et al. (2003) is correct, it is predicted that horizontal eye movements will enhance performance on both conceptual and perceptual explicit (vs. implicit) tests. However, if the type of processing (conceptual vs. perceptual) is 
more important than retrieval intention, then horizontal eye movements are predicted to be more likely to enhance performance on conceptual tests of memory. The reason for this prediction is that previous research has found SIRE effects on tests such as free-recall, cuedrecall and recognition (e.g., Lyle et el., 2008; Lyle, \& Edlin, 2015; Parker \& Dagnall, 2007), that are all classed as conceptual in nature (e.g., Roediger et al., 1989). The only instance of which we are aware that assessed performance on a test that measures perceptual memory by TAP criteria (e.g., word-fragment completion, Christman et al., 2003), did not find an effect of eye-movements. Consequently, if the type of processing has precedence over retrieval orientation, there seemed more grounds for predicting a SIRE effect for conceptual tests.

\section{Method}

\subsection{Design}

The experiment had three between-participant independent variables, each with two levels. The first was the eye movement condition: saccadic horizontal eye movement vs. central fixation (no eye movement). The second was retrieval intention: explicit (intentional) vs. implicit (incidental). The third was processing requirement: conceptual vs. perceptual.

Separate dependent variables were collated for explicit and implicit tests. For the explicit tests, the dependent variables were the number (proportion) of studied items correctly recalled, and the number (proportion) of baseline items recalled. For the implicit tests the dependent variables were the number (proportion) of studied items produced and the number (proportion) of baseline items produced. Priming scores for the implicit tests were represented by the difference between studied and unstudied items produced in the test and were analysed as a function of eye-movements.

\subsection{Participants}


The participants were a total of 200 strongly-right-handed individuals ${ }^{3}$ (50 in each of the four memory test conditions). Handedness was determined by the use of a modified version of the Edinburgh Handedness Inventory (EHI) (Oldfield, 1971) (described below). Strongly-right-handed individuals were those who scored +80 and above on this measure. All participants were recruited from the pool of students from the Faculty of Health, Psychology, and Social Care at Manchester Metropolitan University. None had taken part in any similar research and participation was voluntary.

\subsection{Materials}

The materials comprised the Edinburgh Handedness Inventory (Oldfield, 1971) and a set of category exemplars for the study and test stimuli. The EHI comprises a self-report scale in which respondents indicate their handedness preference when performing a number of manual tasks. A number of different versions of the EHI are in circulation (Edlin, Leppanen, Fain, Hackländer, Hanaver-Torrez, \& Lyle, 2015). These variations pertain to the items within the inventory, the nature of the response scale and the procedure for scoring the inventory. In the current research, the inventory contained a total of ten activities (e.g., writing, drawing, \& throwing) as described by Lyle et al., (2008). Each activity, was accompanied by a five-point Likert scale to indicate handedness preference for each of the ten activities. The points making up the scale were defined as always left (-10), usually left (5), no preference (0), usually right (+5) and always right $(+10)$. The figures in parentheses refer to the item score and thus total scores range between -100 and +100 . This scoring procedure (as opposed to the original EHI scheme) was adopted in-line with recent work (e.g., Brunyé, Mahoney, Augustyn, \& Taylor, 2009; Christman \& Butler, 201; Edlin, et al., 2013, 2015; Lyle et al., 2008; Lyle \& Jacobs, 2010). 
The encoding and test stimuli were taken from the Battig and Montague (1969) norms. Six exemplars from 12 categories (four-footed animal, insect, fruit, alcoholic drink, instrument, sport, colour, metal, body part, bird, item of clothing, and vehicle) were selected as targets. All the selected exemplars were those that did not rank among the six most dominant and were typically much lower. On some occasions, certain exemplars were excluded because they contained two words or were likely to be very unfamiliar to the subjects. The mean (SD) dominance ranking per category was 13.51 (1.82). The total category size (number of exemplars per category) in the listed norms ranged from 31 to 56. The rationale for including only lower dominance exemplars was to avoid ceiling effects on the tests. If only high-ranking exemplars were used, then these would likely be generated on the tests irrespective of prior exposure in the experiment. Thus, to ensure sufficient range for priming, lower ranking items were employed as is typical of similar research. The exemplars themselves were of varying length, ranging from three to eleven letters. The 12 categories were randomly divided into two sets of six categories in order to create two sets (list A and list B) of target stimuli. Only one set served as study stimuli and this was alternated across participants for the purpose of counterbalancing. Each study set contained four additional words for primacy and recency buffers (two each), which were not included in the analysis, and these were placed at the beginning and end of the study lists.

For the conceptual tests (category-cued recall and category-exemplar generation) category labels were provided as cues. For the perceptual tests (word-fragment-cued recall and word-fragment completion) fragmented versions of the stimuli were provided as cues. The word-fragments were created by deleting a proportion of (primarily) internal letters from each word. The mean (SD) proportion of letters deleted was .41 (.08). All category labels and word-fragments were presented at test to allow for the analysis of unstudied items recalled. 
Tests were prepared in the form of booklets with written spaces provided for written responses.

In line with previous research (e.g. Christman et al., 2003; Parker \& Dagnall, 2007) a computer programme was designed to initiate eye movements in the appropriate manner. This was accomplished by flashing a black circle (approximately $4^{\circ}$ of visual angle in diameter) against a white background, either sequentially on the left and right of the screen (saccadic horizontal condition), or on and off in the centre of the screen (central fixation condition). The circle moved (flashed) every 500ms, and in the horizontal condition was located approximately $27^{\circ}$ of visual angle apart, which produced two eye movements per second for the duration of 30 seconds.

\subsection{Procedure}

All participants were tested individually. Participants were informed that they were about to take part in a study investigating how individuals process words. They were not told that their memory would later be tested. Prior to taking part, participants were asked to sign a consent form. The experiment was divided into three phases: encoding, delay (distractor), and test phases. Allocation to experimental conditions was random.

In phase one, participants were exposed to a list of words on a computer monitor. Each of the 36 word stimuli were presented individually for two seconds, and with an interstimulus interval of one second. Stimuli were from either list A or list B. Presentation was pseudo-randomised, with the stipulation that no two exemplars from the same category would appear in succession. Participants were asked to pay full attention to each word as they appeared in turn on the screen.

In the second phase, participants were required to complete a three minute filler task in which they were asked to write down the names of as many towns and cities in Great 
Britain that they could generate. Then, in the final phase, participants allocated to the eye movement condition were given instructions to follow the dot as it appeared back and forth on the left and right of the screen. In this condition, it was emphasised that following the dot should be done by moving their eyes, whilst keeping their head stationary. If allocated to the no eye movement condition they were asked to stare at the dot as it flashed on and off in the centre of the screen. Compliance with these instructions was monitored by the experimenter.

Following 30s of the eye movement condition, participants were allocated to one of the four test conditions: conceptual explicit (category-cued recall), perceptual explicit (wordfragment-cued recall), conceptual implicit (category-exemplar generation), and perceptual implicit (word-fragment completion). Those assigned to the conceptual explicit test were provided with category labels (e.g. four-footed animal, sport, fruit) and were informed that some of these corresponded to words seen during the study phase whilst others did not. They were asked to use the category labels to help them recall as many words as they could from the study phase pertaining to the categories. Participants assigned to the perceptual explicit test were presented with word-fragments and asked to use these cues as an aid to recalling as many studied items as possible. Participants assigned to the conceptual implicit test were again provided with category labels as cues, but asked to respond with the first six corresponding examples which simply 'popped to mind'. Those participants assigned to the perceptual implicit test were provided with word-fragments and asked to complete each one in turn with the first word that 'popped to mind'. Participants assigned to the implicit tests were made aware of the study-test relationship by informing them that they may recognise some of the words that come to mind as originating in the encoding phase. They were told that this is acceptable but to nevertheless continue to follow the given instructions by generating the items that first come to mind. The purpose of highlighting the relationship between study and test aware is to prevent participants from switching to making use of 
intentional retrieval strategies should they become spontaneously aware of this relationship during testing. Previous research has found such instructions to be successful in this regard (McKone \& French, 2001; Parker, Dagnall, \& Coyle, 2007; Ramponi, et al., 2004; Richardson-Klavehn \& Gardiner, 1995, 1996). If participants did revert to making use of intentional retrieval, this would be problematic as it would produce a situation referred to as explicit test contamination. That is, the implicit test becomes contaminated by the use of explicit retrieval strategies; this of course makes interpretation of the findings difficult. The use of instructions such as these is evaluated in the discussion. Following the implicit tests, participants were asked if they had followed the instructions to produce the first response that came to mind. None of the participants were excluded as a result of not following the assigned retrieval instructions. No time limit was placed on the tests, although participants in the implicit conditions were instructed to only spend a few seconds generating examples or completing word-fragments. Upon completion of the tests participants were debriefed about the nature of the study.

\section{Results}

\subsection{Overview of results}

All analyses were based upon the proportion of studied and unstudied items produced at test and were examined separately for each type of test. The analyses themselves consisted of 2(eye movement condition: horizontal vs. central) between-participants x 2 (item type: studied vs. unstudied) within-participants mixed ANOVA. Effect sizes for ANOVA's are reported as partial eta squared $\eta_{p}{ }^{2}$. Effect sizes for simple main effects are reported as Cohen's d. The descriptive statistics can be found in Table 1. 


\subsection{Effects of eye-movements on the four types of test}

For the test of conceptual explicit memory, both main effects were significant, $F(1$, $48)=10.62, p=.002, \eta_{\mathrm{p}}^{2}=.18$, and $F(1,48)=166.21, p \leq .001, \eta_{\mathrm{p}}{ }^{2}=.78$, for eyemovement condition and item type respectively. Importantly, these effects were qualified by an interaction, $F(1,48)=13.55, p=.001, \eta_{\mathrm{p}}^{2}=.22$. Simple main effects were conducted for each item type to assess the effects of eye movements. For unstudied items, the difference was non-significant, $t(48)=0.44, p=.66$. However for studied items, the horizontal condition produced superior recall, $t(48)=4.03, p \leq .001$, Cohen's $d=1.24$. The false recall rate (responding with non-studied exemplars from studied categories) was very low and at floor levels, hence these scores were not subject to analysis. This fact indicates that the higher levels of true recall following horizontal saccades was not simply due to a shift in the subject's report criterion.

For the test of conceptual implicit memory, the main effect of eye movement was not significant, $F(1,48)=0.06, p=.80, \eta_{\mathrm{p}}^{2}=.001$. The effect of item type was significant, $F(1$, $48)=47.97, p \leq .001, \eta_{\mathrm{p}}^{2}=.50$ (showing a larger score for studied items), but the interaction failed to achieve significance, $F(1,48)=0.44, p=.51, \eta_{\mathrm{p}}^{2}=.009$.

The test of perceptual explicit memory revealed no effect of eye movements, $F(1,48)$ $=1.70, p=.20, \eta_{\mathrm{p}}{ }^{2}=.03$. The effect of item type was significant, $F(1,48)=261.94, p \leq$ $.001, \eta_{\mathrm{p}}^{2}=.84$ (showing a larger score for studied items), but the interaction was not significant, $F(1,48)=0.01, p=.91, \eta_{\mathrm{p}}{ }^{2}=.001$.

The test of perceptual implicit memory showed no effect of eye movements, $F(1,48)$ $=0.01, p=.98, \eta_{p}^{2}=.001$. The effect of item type was significant, $F(1,48)=135.93, p \leq$ $.001, \eta_{\mathrm{p}}^{2}=.74$ (showing a larger score for studied items), but the interaction was not significant, $F(1,48)=0.89, p=.35, \eta_{p}^{2}=.02$. 
Priming scores for the implicit tests were calculated and differences between the eyemovement conditions assessed. No effect was found for either the conceptual $[F(1,48)=$ $\left.0.44, p=.51, \eta_{\mathrm{p}}^{2}=.01\right]$ or perceptual test $\left[F(1,48)=0.87, p=.35, \eta_{\mathrm{p}}{ }^{2}=.018\right]$.

\subsection{Additional considerations and summary of the results.}

It is unlikely that the null effect of eye movements on the tests other than categorycued recall reflected a lack of power because robust effects were obtained with the conceptual explicit (with equivalent subject numbers). Additionally, calculations indicated that the power to detect a difference equivalent to the one found with category-cued recall was high at .98. In fact, substantial power of over .80 was achievable for an effect only $2 / 3$ rds the size of the one obtained for category-cued recall.

Finally, Baysian analyses were used to assess the evidence in favour of the null effects of eye movements being true (Dienes , 2011, 2014). The likelihood of the obtained data given the null:alternative hypothesis being true was 13.03:03.70 $($ Bayes Factor $=0.28)$, for the conceptual implicit test, 10.60:03.80 (Bayes Factor $=0.36)$, for the perceptual implicit test and 07.83:4.89 (Bayes Factor $=0.62$ ), for the perceptual explicit test. In all cases, evidence was clearly in favour of the null hypothesis.

In summary, the results found a significant influence of eye movements for categorycued recall, but not for the matched test of category-exemplar generation or either of the perceptual tests. In particular, SIRE effects were observed when the test was conceptual and intentional retrieval was required. In addition, this effect pertained only to studied (vs. unstudied) exemplars.

\section{Discussion}

\subsection{Main findings from the current experiment}


The current experiment found that SIRE effects were observed only on the test of conceptual explicit memory. That is, eye movements enhanced retrieval when the test recruited conceptual processing and the retrieval orientation was intentional (explicit). SIRE effects were not found on either of the implicit tests nor an explicit test that required perceptual processing. Of additional interest is the finding that eye movements did not affect baseline responding rates on any of the tests. A conclusion to be derived from this is that eye movements do not influence lexical (perceptual tests) or semantic (conceptual tests) memory retrieval independently of recent exposure (priming). However, the most important findings worthy of discussion pertain to the effects of eye movements on priming (implicit) and recall (explicit) as a function of recent exposure. The theoretical and methodological implications of the present results are dealt with below.

\subsection{Theoretical context of the results}

These findings provide partial support for the claim of Christman et al. (2003), who hypothesised eye movement effects to influence explicit, but not implicit memory retrieval. However, this support is not unequivocal because word-fragment cued recall (an explicit test) was not enhanced by eye movements. Rather, the current results suggest that the effects of eye movements on tests of explicit memory dissociate as a function of processing demands at test. This outcome implies that both retrieval intention and processing demands are important dimensions when assessing the scope of SIRE effects.

In this context, it is important to consider how theoretical accounts of SIRE might explain these findings. In relation to the hemispheric interaction model of Christman and colleagues, it is claimed that horizontal eye movements increase hemispheric interaction and performance on tasks that are considered to be dependent on such interactions; this includes explicit memory. However, in the present experiment, this was found only for conceptual 
explicit memory. To the extent this finding extends across a range of similar tasks, the predictions of HERA model may need to be adapted. One possibility relates to the notion that saccadic horizontal eye movements selectively increase hemispheric activity in the frontal regions of the brain (O’Driscoll et al., 1998). Research into the neural activity associated with conceptual (vs. perceptual) processing demonstrates changes within the prefrontal cortex (Bergstrom et al., 2013; Gabrieli et al., 1996). More specifically, areas including the left inferior frontal gyrus, and the ventromedial and dorsomedial prefrontal cortices (Binder et al., 2009; Wei et al., 2012). In contrast, perceptual memory processing is associated with activity in posterior occipitotemporal regions (Keane et al., 1995; Slotnick, 2004; Slotnick \& Schacter, 2006). Indeed, double dissociations have been found between processing type (conceptual vs. perceptual) and locus of brain damage (frontal vs. occipital) (Gong et al., 2015). This is not to say that conceptual knowledge is stored or represented in the frontal regions (Patterson, Nestor, \& Rogers, 2007; Visser \& Lambon Ralph, 2011), but rather is processed by frontal executive control subregions, that are hypothesised to constitute semantic working memory (Martin \& He, 2004; Rose, Craik, \& Buchsbaum, 2015). In particular, these regions are thought to be involved in the retrieval and selection of appropriate conceptual information that provides a basis for the formation of a coherent semantic representation (Badre \& Wagner, 2002; 2007). In this context, a modified HERA proposal could be that hemispheric interaction is of importance for explicit memory, as in the original formulation, but only when retrieval requires the (re)processing of conceptual information. The latter of which, as noted, has often been associated with frontal regions. Within this modified account, eye movements effect neither conceptual processing nor explicit (intentional) retrieval independently, but in a joint manner.

As an adjunct explanation, SIRE effects may have been obtained only on the test of conceptual explicit memory because of other processing differences between explicit and 
implicit retrieval. Mulligan $(2002 ; 2006)$ provides evidence that conceptual explicit and implicit memory can be dissociated as a function of the item-specific and relational processing (Hunt \& Einstein, 1981; Hunt \& McDaniel, 1993). Item-specific processing refers to the encoding of attributes unique to each stimulus item. Relational processing refers to the encoding of similarities between items. The encoding of such information has consequences for memory retrieval processes and the type of tests used to assess memory. With regard to memory retrieval, the use of relational information provides a basis for the formulation of a retrieval plan and the traversing of associative links between items stored in memory. This in turn provides a basis for the recovery of encoded information based on a subset of cues. The processing of item-specific information then allows for discrimination to take place between encoded (and non-encoded) attributes. In this context, item-specific processing is particularly effective in discriminating between items that have (vs. have not) been studied and can serve to improve mnemonic accuracy on tests that require such forms of discrimination. Within this framework, Mulligan $(2002,2006)$ argues and provides evidence that explicit conceptual tests require the processing of both relational and item-specific information, whereas implicit conceptual tests are primarily dependent on only relational information.

This account provides a potential explanation of the observed dissociations between tests that are conceptual and differ only in terms of retrieval orientation. As applied to the current findings, it could be hypothesised that eye movements enhance the processing of item-specific information (differentiating between studied and non-studied exemplars) in the context of relational processing (using categories to cue relational information pertaining to exemplars within each category class). In particular, category-cued recall requires finer discriminations in mnemonic processing than category-exemplar generation, as the former requires the production of words that correspond to a given category and appeared on the study list. In contrast, category-exemplar generation requires only the production of examples 
from the category. It has been suggested that these forms of processing are implemented in different neural locations with relational processing associated with the dorsolateral prefrontal cortex and item-specific processing in the ventrolateral cortex (Badre \& Wagner, 2007; Murray \& Ranganath, 2007; Ragland et al., 2015; Wagner, Maril, Bjork, \& Schacter, 2001). However, precisely how these regions contribute to performance in conceptual explicit and implicit tasks remains relatively unexplored. Direct comparisons between conceptual explicit and implicit tasks reveal functional neuroanatomical differences (e.g., Blaxton, Bookheimer, Zeffiro, Figlozzi, \& Gaillard, 1996; Donaldson, Peterson \& Buckner, 2001; Voss \& Paller, 2008) but these have not been unequivocally linked to relational and itemspecific processing.

In spite of the above arguments, and their applicability to dissociations between conceptual tests, they do not so readily apply to perceptual tests or dissociations between perceptual and conceptual tests. Perhaps, the notion of processing differences in the context of relational information is of key importance. If so, this may explain the lack of effect on the perceptual test used here that comprised of perceptual item-specific measures (in which itemspecific cues are presented with the requirement for relational processing) (Moscovitch, Goshen-Gottstein, \& Vriezen, 1994). Consequently, a combination of test requirements need to be met before SIRE effects are found.

Lyle and colleagues (e.g., Lyle \& Edlin, 2015) proposed a different account of SIRE effects that arise as the result of top-down or executive processes during retrieval. In particular, such processes are more likely to be involved when retrieval takes place in a competitive context, such as when cues activate multiple representations from which selection is required. This is especially important when the probability of the recovery of a target item is reduced by the retrieval of competing, but non-target, items (Lyle \& Edlin, 2015). 
More general support for this idea comes from Edlin and Lyle (2013), who found that horizontal saccades enhanced performance in the Revised Attention Network Task (ANT-R; Fan et al., 2009) under high (vs. low) conflict conditions. This prompted the authors to propose that SIRE is a specific example of the broader phenomenon of Saccadic-Induced Cognitive Enhancement (SICE). This implies that horizontal saccades temporarily enhance cognitive or executive functioning in a more general sense, primarily by increasing activity in the PFC and subsequent connectivity with posterior neural regions, such as the parietal lobes. The current findings can be considered within this context, as results for category-cued recall may reflect an enhancement in a memory test that requires top-down processing to retrieve studied exemplars in the context of competing but non-studied exemplars.

If the contribution of top-down processing in SIRE effects is correct, the observed dissociation between explicit conceptual and perceptual tests should only arise under particular conditions in which top-down control is required to resolve processing conflicts in the face of non-target competition. Consequently, dissociations between tests of memory may be more accurately characterised in terms of differences in the degree of response competition. However, the current experiment was not designed to assess the specific role of response competition. From the perspective of the top-down processing explanation, this is a requirement for future work and could be examined under both explicit and implicit retrieval conditions.

\subsection{Caveats; The question of perceptual explicit memory and test awareness}

However, before deriving conclusions concerning either of the above accounts, a number of other factors need to be taken into consideration that broaden the scope of the arguments and may further impact upon the explanations offered. Firstly, why was no effect of eye movements found on explicit perceptual memory when other research has 
“apparently" demonstrated such influences? For example, Brunye et al. (2009) found that horizontal saccades improved the accuracy of yes/no recognition performance for visual scenes. That recognition is considered to be an explicit test (by virtue of testing instructions) and perceptual (by virtue of the visual nature of the stimuli), then the conclusion that horizontal saccades improve perceptual explicit memory seems to be appropriate. However, recognition of pictorial information depends not only on the retrieval of perceptual information, but is influenced by the processing of conceptual information (Sternberg, 2006). Hence, picture recognition may not be the most appropriate index of explicit perceptual memory. More apt measures are those that show sensitivity to study-test changes in perceptual differences, without variation in performance as a function of encoding based factors such as levels of processing or read/generate manipulations. To be fair, such tests are difficult to design as intentional/explicit retrieval instructions may engage conceptual processing automatically. Previous examples of explicit perceptual test include graphemic cued-recall and recognition (Blaxton, 1989; Challis, Velichkovsky, \& Craik, 1996). These tests were not used in the current work as the decision to employ word-fragment completion as the implicit perceptual test had already been made. The reason for this was that this test displayed the appropriate properties of being not only implicit, but also sensitive to variations in perceptual-surface features such as modality (Blum \& Yonelinas, 2001). Consequently, the most appropriate matched test in terms of retrieval cues was word-fragment cued-recall. Of course, this must not be taken to indicate that other types of test should not be used. It is vital that a wider range of tests are examined that allow for an examination of the boundary conditions of SIRE effects in theoretically meaningful ways.

Secondly, the implicit test instructions made all subjects aware of the nature of the study-test relationship and thus equating study-test awareness. The reason for this was to ensure that subjects did not become aware spontaneously of this relationship and alter their 
retrieval strategy (thus producing explicit contamination in the implicit test). This procedure was important in the current experiment because the alternative of masking this relationship and assessing retrieval strategies by use of a post-test questionnaire, often produces an unequal division between test aware (vs. unaware) groups and for perceptual (vs. conceptual) tests. The approach used here is not in itself problematic as past research has shown that explicit-implicit dissociations can be obtained when study-test awareness is held constant (McKone \& French, 2001; Parker, et al., 2007; Ramponi, et al., 2004; Richardson-Klavehn \& Gardiner, 1995, 1996). In spite of this, particular complications might arise insofar as awareness of the relationship between study and test has been shown to lead to increased priming effects (Mace, 2005), and in addition, does not allow for a clear separation between implicit memory accompanied (vs. not accompanied) by awareness. The latter distinction needs to be considered more closely in future work. Ideally, the implications of this difference could be assessed by the comparison of aware (vs. unaware) groups, based on post-test divisions alongside test conditions in which all subjects are informed of the studytest relationship. Indeed, it may be valuable to manipulate the extent of awareness by variation of the testing conditions (Mace, 2005).

Returning briefly to the notion of explicit contamination, it could be argued that making subjects study-test aware increases the chances of this occurring. This is unlikely in the current experiment because subjects indicated making use of appropriate strategies after the implicit tests. In addition, for the conceptual implicit test, if explicit retrieval strategies were being deployed, then parallel effects of the manipulated variable (eye-movements) would have been found. In contrast, there was no hint of any effect of eye movement on conceptual priming.

\subsection{Encoding processes and their implications for retrieval}


Before concluding, it is worth mentioning that the encoding conditions of the present experiment required simply the reading of words as they appeared on the screen. No attempt was made to manipulate encoding strategies during study, as the focus of the current experiment assessed only whether the effects of eye-movements differed as a function of the retrieval task. This could be of importance and needs to be considered in future work on SIRE effects. The reason for this relates to some past work on the effects of handedness on memory that show superior explicit memory in mixed-handed (vs. strongly right-handed) individuals. According to theoretical explanation of Christman and colleagues (e.g., Christman, \& Propper, 2010) mixed-handed persons possess greater levels of baseline hemispheric interaction (see also footnote 2). By this account, as SIRE effects are also dependent on hemispheric interaction, then both handedness and SIRE effects are dependent on similar mechanisms. However, recent work has found that handedness effects on explicit memory arose only when the encoding task recruited conceptual processing (Christman \& Butler, 2011). Consequently, it would be worth assessing if eye-movement effects are influenced by additional variables that vary the encoding tasks.

\subsection{Conclusion}

From a more general perspective, the current findings indicate that SIRE effects are far from being ubiquitous. Instead, such influences are likely to be dependent on a range of experimental design features that are only just beginning to be understood. In the research presented here, these factors pertained to retrieval orientation and the overlap between study and test conditions. An examination of the role of a wider range of influences is essential from a theoretical point of view in terms of extending our understanding of SIRE effects. 
Babiloni, C., Vecchio, F., Cappa, S., Pasqualetti, P., Rossi, S., Miniussi, C., et al. (2006). Functional frontoparietal connectivity during encoding and retrieval processes follows the HERA model: A high-resolution study. Brain Research Bulletin, 68, 203-212.

Badgaiyan, R. D. (2000). Neuroanatomical organization of perceptual memory: an fMRI study of picture priming. Human Brain Mapping, 10, 197-203.

Badre, D. and Wagner, A. D. (2002). Semantic retrieval, mnemonic control, and prefrontal cortex. Behavioral and Cognitive Neuroscience Reviews, 1, 206-218.

Badre, D., \& Wagner, A. D. (2007). Left ventrolateral prefrontal cortex and the cognitive control of memory. Neuropsychologia, 45, 2883-2901.

Battig, W. F., \& Montague, W. E. (1969). Category norms for verbal items in 56 categories: A replication and extension of the Connecticut norms. Journal of Experimental Psychology, 80, 1-46.

Bergström, Z. M., Henson, R. N., Taylor, J. R., \& Simons, J. S. (2013). Multimodal imaging reveals the spatiotemporal dynamics of recollection. Neuroimage, 68 , $141-153$.

Binder, J. R., Desai, R. H., Graves, W. W., \& Contant, L. L. (2009). Where is the semantic system? A critical review and meta-analysis of 120 functional neuroimaging studies. Cerebral Cortex, 19, 2767-2796.

Blaxton, T. A. (1989) Investigating dissociations among memory measures: Support for a transfer-appropriate framework. Journal of Experimental Psychology: Learning, Memory, and Cognition, 15, 657-68.

Blaxton, T. A., Bookheimer, S. Y., Zeffiro, T. A., Figlozzi, C. M., Gaillard, W. D., \& Theodore, W. H. (1996). Functional mapping of human memory using PET: Comparisons of conceptual and perceptual tasks. Canadian Journal of Experimental Psychology, 50, 42-56. 
Blum, D., \& Yonelinas, A. P. (2001). Transfer across modality in perceptual implicit memory. Psychonomic Bulletin \& Review, 8, 147-154.

Brunyé, T. T., Mahoney, C. R., Augustyn, J. S., \& Taylor, H. A. (2009). Horizontal saccadic eye movements enhance the retrieval of landmark shape and location information. Brain \& Cognition, 70, 279-288.

Buckner, R. L., Petersen, S. E., Ojemann, J. G., Miezin, F. M., Squire, L. R., \& Raichle, M. E. (1995). Functional anatomical studies of explicit and implicit memory retrieval tasks. Journal of Neuroscience, 15, 12-29.

Cabeza, R. (1994). A dissociation between two implicit conceptual tests supports the distinction between types of conceptual processing. Psychonomic Bulletin \& Review, 4, 505-508.

Cabeza, R. (2008). Role of parietal regions in episodic memory retrieval: The dual attentional processes hypothesis. Neuropsychologia, 46, 1813-1827.

Cabeza, R., \& Moscovitch, M. (2013). Memory systems, processing modes, and components: functional neuroimaging evidence. Perspectives on Psychological Science, 8, 49-55.

Challis, B. H., Velichkovsky, B. M., \& Craik, F. I. M. (1996). Levels-of-processing effects on a variety of memory tasks: New findings and theoretical implications. Consciousness and Cognition, 5, 142-164.

Christman, S. D., \& Butler, M. (2011). Mixed-handedness advantages in episodic memory obtained under conditions of intentional learning extend to incidental learning. Brain \& Cognition, 77, 17-22.

Christman, S. D., Garvey, K. J., Propper, R. E., \& Phaneuf, K. A. (2003). Bilateral eye movements enhance the retrieval of episodic memories. Neuropsychology, 17, 221229. 
Christman, S. D., \& Propper, R. E. (2010). Episodic memory and hemispheric interaction: Handedness and eye movements. In G.M. Davies \& D.B. Wright (Eds.), Current issues in applied memory research (pp. 185-205). Hove: Psychology Press.

Christman, S. D., Propper, R. E., \& Brown, T. J. (2006). Increased interhemispheric interaction is associated with earlier offset of childhood amnesia. Neuropsychology, $20,336-345$.

Christman, S. D., Propper, R. E., \& Dion, A. (2004). Increased interhemispheric interaction is associated with deceased false memories in a verbal converging semantic associates paradigm. Brain \& Cognition, 56, 313-319.

Ciaramelli, E., Grady, C. L., \& Moscovitch, M. (2008). Top-down and bottom-up attention to memory: A hypothesis (AtoM) on the role of the posterior parietal cortex in memory retrieval. Neuropsychologica, 46, 1828-1851.

Corbetta, M., \& Shulman, G. L. (2002). Control of goal directed and stimulus-driven attention in the brain. Nature Reviews Neuroscience, 3, 201-215.

Corkin, S. (2002). What's new with the amnesic patient H.M.? Nature Reviews: Neuroscience, 3, 153-160.

Craik, F. I. M., Moscovitch, M., \& McDowd, J. M. (1994). Contributions of surface and conceptual information to performance on implicit and explicit memory tasks. Journal of Experimental Psychology: Learning, Memory, \& Cognition, 20, $864-875$.

Craik, F. I. M., \& Tulving, E. (1975). Depth of processing and the retention of words in episodic memory. Journal of Experimental Psychology General, 104, 268-294.

Danion, J. M., Meulemans, T. \& Kauffmann-Muller, F. (2001). Intact implicit learning in schizophrenia. American Journal of Psychiatry, 158, 944-948. 
Daum, I., Channon, S., \& Canavar, A. (1989). Classical conditioning in patients with severe memory problems. Journal of Neurology and Neurosurgery Psychiatry, 52, 47-51.

Dew, I. T. Z., \& Cabeza, R. (2011). The porous boundaries between explicit and implicit memory: behavioral and neural evidence. Annals of the New York Academy of Sciences Issue: The Year in Cognitive Neuroscience, 1224, 174-190.

Dienes, Z. (2011). Bayesian versus orthodox statistics: which side are you on? (2011). Perspectives in Psychological Science, 6, 274-290.

Dienes, Z. (2014). Using Bayes to get the most out of non-significant results. Frontiers in Psychology, 5:781. doi: 10.3389/fpsyg.2014.00781

Donaldson, D. I., Petersen, S. E., Buckner, R. L., (2001). Dissociating memory retrieval processes using fMRI: evidence that priming does not support recognition memory. Neuron, 31, 1047-1059.

Donaldson, D. I., Wheeler, M. E., \& Petersen, S. E. (2010). Remember the source: dissociating frontal and parietal contributions to episodic memory. Journal of Cognitive Neuroscience, 2, 377-391.

Edlin, J. M., Leppanen, M. L., Fain, R. J., Hackländer, R. P., Hanaver-Torrez, S. D., \& Lyle, K. B. (2015). On the use (and misuse?) of the Edinburgh Handedness Inventory. Brain and Cognition, 94, 44-51.

Edlin, J. M., \& Lyle, K. B. (2013). The effect of repetitive saccade execution on the attention network test: enhancing executive function with a flick of the eyes. Brain \& Cognition, 81, 345-351.

Fan, J., Gu, X., Guise, K. G., Liu, X., Fossella, J., Wang, H., \& Posner, M. I. (2009). Testing the behavioral interaction and integration of attentional networks. Brain \& Cognition, 70, 209-220. 
Gabrieli, J. D. E., Desmond, J. E., Demb, J. B., Wagner, A. D., Stone, M. V., Vaidya, C. J., \& Glover, G. H. (1996). Functional magnetic resonance imaging of semantic memory processes in the frontal lobes. Psychological Science, 7, 278-283.

Gabrieli, J. D. E., Vaidya, C. J., Stone, M., Francis, W. S., Thompson-Schill, S. L., Fleischman, D. A., Tinklenberg, J. R., Yesavage, J. A., \& Wilson, R. S. (1999). Convergent behavioural and neuropsychological evidence for a distinction between identification and production forms of repetition priming. Journal of Experimental Psychology: General, 128, 479-498.

Gagnon, G., Blanchet, S., Grondin, S., \& Schneider, C. (2010). Paired-pulse transcranial magnetic stimulation over the dorsolateral prefrontal cortex interferes with episodic encoding and retrieval for both verbal and non-verbal materials. Brain Research, $1344,148-158$.

Glisky, E. L., \& Schacter, D. L. (1987). Acquisition of domain specific knowledge in organic amnesia: Training for computer-related work. Neuropsychologia, 25, 893-906.

Glisky, E. L., \& Schacter, D. L. (1988). Long-term retention of computer learning by patients with memory disorders. Neuropsychologia, 26, 173-178.

Glisky, E. L., \& Schacter, D. L. (1989). Extending the limits of complex learning in organic amnesia: Computer training in a vocational domain. Neuropsychologia, 27, $107-120$.

Glisky, E. L., Schacter, D. L., \& Tulving, E. (1986). Computer learning by memoryimpaired patients: Acquisition and retention of complex knowledge. Neuropsychologia, 24, 313- 328.

Graf, P., \& Mandler, G. (1984). Activation makes words more accessible but not necessarily more retrievable. Journal of Verbal Learning \& Verbal Behaviour, 23, 553-568. 
Graf, P., Mandler, G., \& Haden, P.E. (1982). Simulating amnesic symptoms in normal subjects. Science, 218, 1243-1244.

Graf, P., Squire, L. R., \& Mandler, G. (1984). The information that amnesic patients do not forget. Journal of Experimental Psychology: Learning, Memory \& Cognition, 10, $164-178$.

Gong, L., Wang, J., Yang, X., Feng, L., Li, X., Gu, C., Wang, M., Hu, J., \& Cheng, H. (2016). Dissociation between Conceptual and Perceptual Implicit Memory: Evidence from Patients with Frontal and Occipital Lobe Lesions. Frontiers in Human Neuroscience, 9:722. doi: 10.3389/fnhum.2015.00722

Habib, R., Nyberg, L., \& Tulving, E. (2003). Hemispheric asymmetries of memory: The HERA model revisited. Trends in Cognitive Sciences, 7, 241-245.

Hamann, S. B. (1990). Levels of processing effects in conceptually-driven implicit tasks. Journal of Experimental Psychology: Learning, Memory, \& Cognition, 16, 970-977.

Hayman, G. C. A., \& Rickards, C. (1995). A dissociation in the effects of study modality on tests of implicit and explicit memory. Memory \& Cognition, 23, 95-112.

Henson, R. N. (2003). Neuroimaging studies of priming. Progress in Neurobiology, 70, 5381.

Hayman, G. C. A., \& Rickards, C. (1995). A dissociation in the effects of study modality on tests of implicit and explicit memory. Memory \& Cognition, 23, 95-112.

Hou, M., Safron, A., Paller, K. A., \& Guo, C. (2013). Neural correlates of familiarity and conceptual fluency in a recognition test with ancient pictographic characters. Brain Research, 1518, 48-60.

Hunt, R. R., \& Einstein, G. O. (1981). Relational and item-specific information in memory. Journal of Verbal Learning \& Verbal Behavior, 19, 497-514. 
Hunt, R. R., \& McDaniel, M. A. (1993). The enigma of organisation and distinctiveness. Journal of Memory \& Language, 32, 421-455.

Jacoby, L. L. (1983). Remembering the data: Analyzing interactive processes in reading. Journal of Verbal Learning and Verbal Behavior, 22, 485-508.

Jacoby, L. L. (1984). Incidental versus intentional retrieval: Remembering and awareness as separate issues. In L. R. Squire \& N. Butters (Eds.) Neuropsychology of Memory, (pp. 145-156). New York: Guilford Press.

Jacoby, L. L., \& Dallas, M. (1981). On the relationship between autobiographical memory and perceptual learning. Journal of Experimental Psychology: General, 110, 306340.

Java, R. I. (1994). States of awareness following word stem completion. European Journal of Cognitive Psychology, 6, 77-92.

Keane, M. M., Gabrieli, J. D. E., Mapstone, H.C., Johnson, K. A., \& Corkin, S. (1995). Double dissociation of memory capacities after bilateral occipital-lobe or medial temporal-lobe lesions. Brain, 118, 1129-1148.

Lyle, K. B., \& Edlin, J. M. (2015). Why does saccade execution increase episodic memory retrieval? A test of the top-down attentional control hypothesis. Memory, 23, 187-202.

Lyle, K. B., Hanaver-Torrez, S. D., Hackländer, R. P., \& Edlin, J. M. (2012). Consistency of handedness, regardless of direction, predicts baseline memory accuracy and potential for memory enhancement. Journal of Experimental Psychology: Learning, Memory and Cognition, 38, 187-193.

Lyle, K. B., \& Jacobs, N. (2010). Is saccade-induced retrieval enhancement a potential means of improving eyewitness evidence? Memory, 18, 581-594. 
Lyle, K. B., Logan, J. M., \& Roediger, H. L. (2008). Eye movements enhance memory for individuals who are strongly right-handed and harm it for individuals who are not. Psychonomic Bulletin \& Review, 15, 515-520.

Lyle, K. B., \& Martin, J. M. (2010). Bilateral saccades increase intrahemispheric processing but not interhemispheric interaction: Implications for saccade-induced retrieval enhancement. Brain \& Cognition, 73, 128-134.

Lyle, K. B., \& Orsborn, A. E. (2011). Inconsistent handedness and saccade execution benefit face memory without affecting interhemispheric interaction. Memory, 19, 613-624.

Mace, J. H. (2005). Experimentally manipulating the effects of involuntary conscious memory on a priming task. The American Journal of Psychology, 118, 159-182.

Mandler, G., Graf, P., \& Kraft, D. (1986). Activation and elaboration effects in recognition and word priming. Quarterly Journal of Experimental Psychology, 38, 645-662.

Martin, R. C., \& He, T. (2004). Semantic short-term memory and its role in sentence processing: A replication. Brain \& Language, 89, 76-82.

Matzke, D., Nieuwenhuis, S., van Rijn, H., Slagter, H.A., van der Molen, M.W., \& Wagenmakers, E.J. (2015). The effect of horizontal eye movements on free recall: A preregistered adversarial collaboration. Journal of Experimental Psychology: General. 15, 144, e1-e15. Doi10.1037/xge0000038

McBride, D. M., \& Shoudel, H. (2003). Conceptual processing effects on automatic memory. Memory \& Cognition, 31, 393-400.

McKone, E., \& French, B. (2001). In what sense is implicit memory "episodic"? The effect of reinstating environmental context. Psychonomic Bulletin \& Review, 8, 806-811.

Moscovitch, M.. Goshen-Gottstein. Y, \& Vriezen, E. (1994). Memory without conscious recollection: A tutorial review from a neuropsychological perspective. In C. Umilti \& 
M. Moscovitch (Eds.) Attention and Performance, vol. 15, Conscious and nonconscious information processing. (pp. 619-669). Cambridge: WT Press.

Mulligan, N. W. (1998). The role of attention during encoding in implicit and explicit memory. Journal of Experimental Psychology: Learning, Memory \& Cognition, 24, $27-47$.

Mulligan, N. W. (2002). The effects of generation on conceptual implicit memory. Journal of Memory \& Language, 47, 327-342.

Mulligan, N. W. (2006). Conceptual implicit memory and the item-specific - relational distinction. In R.R. Hunt \& J.B. Worthen (Eds.), Distinctiveness and Memory. (pp.183-210). New York: Oxford University Press.

Mulligan, N. W. (2012). Differentiating between conceptual implicit and explicit memory: a crossed double dissociation between category-exemplar production and categorycued recall. Psychological Science, 23: 404, DOI: 10.1177/ 0956797611433335.

Mulligan, N. W., \& Besken, M. (2013). Implicit memory. In D. Reisberg. (Ed.), The Oxford Handbook of Cognitive Psychology. (pp 220-231). Oxford: Oxford University Press.

Murray, L. J., \& Ranganath, C. (2007). The dorsolateral prefrontal cortex contributes to successful relational memory encoding. The Journal of Neuroscience, 27, 55155522.

Nieuwenhuis, S., Elzinga, B. M., Ras, P. H., Berends, F., Duijs, P., Samara, Z., \& Slagter, H. A. (2013). Bilateral saccadic eye movements and tactile stimulation, but not auditory stimulation, enhance memory retrieval. Brain \& Cognition, 81, 52-56.

Nyberg, L., Cabeza, R., \& Tulving, E. (1996). PET studies of encoding and retrieval: The HERA model. Psychonomic Bulletin \& Review, 3, 135- 148.

O’Driscoll, G. A., Strakowski, S. M., Alpert, N. M., Matthysse, S. W., Rauch, S. L., Levy, D.L., et al. (1998). Differences in cerebral activation during smooth pursuit and 
saccadic eye movements using positron-emission tomography. Biological Psychiatry, $44,685-689$.

Oldfield, R. C. (1971). The assessment and analysis of handedness: The Edinburgh inventory. Neuropsychologia, 9, 97-113.

Parker, A., Buckley, S., \& Dagnall, N. (2009). Reduced misinformation effects following saccadic bilateral eye movements. Brain \& Cognition, 69, 89-97.

Parker, A., \& Dagnall, N. (2007). Effects of bilateral eye movements on gist based false recognition in the DRM paradigm. Brain \& Cognition, 63, 221-225.

Parker, A., \& Dagnall, N. (2010). Effects of handedness and saccadic bilateral eye movements on components of autobiographical recollection. Brain \& Cognition, 73, 93-101.

Parker, A., \& Dagnall, N. (2012). Effects of saccadic bilateral eye movements on memory in children and adults: An exploratory study. Brain and Cognition, 78, 238-247.

Parker, A., Dagnall, N., \& Coyle, A. M. (2007). Environmental context effects in conceptual explicit and implicit memory. Memory, 15, 423-434.

Parker, A., Dagnall, N., \& Munley, G. (2012). Encoding tasks dissociate the effects of divided attention on category-cued recall and category-exemplar generation. Experimental Psychology, 59, 124-131.

Parker, A., Parkin, A., \& Dagnall, N. (2013). Effects of saccadic bilateral eye movements on episodic and semantic autobiographical memory fluency. Frontiers in Human Neuroscience, 7:630. doi: 10.3389/fnhum.2013.00630.

Parker, A., Parkin, A., \& Dagnall, N. (2017). Effects of Handedness \& Saccadic Bilateral Eye Movements on the Specificity of Past Autobiographical Memory \& Episodic Future Thinking. Brain \& Cognition, 114, 40-51. 
Parker, A., Relph, S., \& Dagnall, N. (2008). Effects of bilateral eye movements on the retrieval of item, associative and contextual information. Neuropsychology, 22, 136145.

Patterson, K., Nestor, P. J., \& Rogers, T. T. (2007). Where do you know what you know? The representation of semantic knowledge in the human brain. Nature Reviews Neuroscience, 8, 976-987.

Phaf, H. (2016). Replication requires psychological rather than statistical hypotheses: The case of eye movements enhancing word recollection. Frontiers in Psychology, 7:2023. doi: 10.3389/fpsyg.2016.02023

Phaf, H. (2017). Eye movements enhance recollection of re-imagined negative words: A link between EMDR and SIRE? Journal of Experimental Psychopathology, In Press.

Propper, R. E., Pierce, J., Bellorado, N., Geisler, M. W., \& Christman, S. D. (2007). Effect of bilateral eye movements on frontal interhemispheric gamma EEG coherence: Implications for EMDR therapy. Journal of Nervous and Mental Disease, 195, 785 788.

Ragland, J. D., Ranganath, C., Harms, M, et al. (2015). Functional and neuroanatomic specificity of episodic memory dysfunction in schizophrenia: a functional magnetic resonance imaging study of the relational and item-specific encoding task. JAMA Psychiatry, 72, 909-916.

Ramponi, C., Richardson-Klavehn, A., \& Gardiner, J. M. (2004). Levels of processing and age affect involuntary conceptual priming of weak but not strong associates. Experimental Psychology, 51, 159-164.

Ramponi, C., Richardson-Klavehn, A., \& Gardiner, J.M. (2007). Component processes of conceptual priming and associative cued recall: The roles of pre-existing 
representations and depth of processing. Journal of Experimental Psychology: Learning, Memory, \& Cognition, 33, 843-862.

Richardson-Klavehn, A., \& Gardiner, J. M. (1995). Retrieval volition and memorial awareness in stem completion: An empirical analysis. Psychological Research, 57, $166-178$.

Richardson-Klavehn, A., \& Gardiner, J. M. (1996). Cross modality priming in stem completion reflects conscious memory, but not voluntary memory. Psychonomic Bulletin \& Review, 3, 238-244.

Richardson-Klavehn, A., Gardiner, J.M., \& Java, R.I. (1994). Involuntary conscious memory and the method of opposition. Memory, 2, 1-29.

Richardson-Klavehn, A., Gardiner, J.M., \& Java, R.I. (1996). Memory: Task dissociations, process dissociations and dissociations of consciousness. In G. Underwood. (Ed.), Implicit Cognition, (pp. 85-158). Oxford: Oxford University Press.

Roediger, H. L. (1990). Implicit memory: Retention without awareness. American Psychologist, 45, 1043-1056.

Roediger, H. L., \& Amir, N. (2005). Implicit memory tasks: Retention without conscious recollection. In A. Wenzel \& D. C. Rubin (Eds.), Cognitive methods and their application to clinical research (pp.129-151). American Psychological Association: Washington DC.

Roediger, H. L., \& Blaxton, T. A. (1987). Effects of varying modality, surface features, and retention interval on priming in word-fragment completion. Memory \& Cognition, $15,379-388$.

Roediger, H. L., \& Geraci, L. (2005). Implicit memory tasks in cognitive research. In A. Wenzel \& D. C. Rubin (Eds.), Cognitive methods and their application to clinical research (pp. 129-151). American Psychological Association: Washington DC. 
Roediger, H. L., \& McDermott, K. B. (1993). Implicit memory in normal human subjects. In F. Boller \& J. Grafman (Eds.), Handbook of neuropsychology, (Vol. 8, pp. 63-131). Amsterdam: Elsevier.

Roediger, H. L., Weldon, M. S., \& Challis, B. H. (1989). Explaining dissociations between implicit and explicit measures of retention: A processing account. In H. L Roediger \& F. I. M. Craik (Eds.), Varieties of memory and consciousness. Essays in honour of Endel Tulving, (pp. 3-36). Hillsdale N J: Erlbaum.

Roediger, H. L., Weldon, M. S., Stadler, M. L., \& Riegler, G. L. (1992). Direct comparison of implicit memory tests: Word fragment and word stem completion. Journal of Experimental Psychology: Learning, Memory, \& Cognition, 18, 1251-1269.

Rose, N. S., Craik, F. I. M. \& Buchsbaum, B. (2015). Levels of processing in working memory: Differential involvement of frontotemporal networks. Journal of Cognitive Neuroscience, 27, 522-532.

Rossi, S., Innocenti, I., Polizzotto, N.R., Feurra, M., De Capua, A., Ulivelli, M., et al. (2011). Temporal dynamics of memory trace formation in the human prefrontal ortex. Cerebral Cortex, 21, 368-373.

Rossi, S., Pasqualetti, P., Zito, G., Vecchio, F., Cappa, S. F., Miniussi, C., et al. (2006). Prefrontal and parietal cortex in human episodic memory: An interference study by repetitive transcranial magnetic stimulation. European Journal of Neuroscience, 23, 793-800.

Rugg, M. D. \& A. P. Yonelinas. (2003). Human recognition memory: a cognitive neuroscience perspective. Trends in Cognitive Sciences 7, 313-319.

Samara, Z., Elzinga, B. M., Slagter, H.A., \& Nieuwenhuis, S. (2011). Do horizontal saccadic eye movements increase interhemispheric coherence? Investigation of a 
hypothesized neural mechanism underlying EMDR. Frontiers in Psychiatry, 2, 4. doi:10.3389/fpsyt.2011.00004.

Schacter, D. L., Bowers, J., \& Booker, J. (1989). Intention, awareness, and implicit memory: The retrieval intentionality criterion. In S. Lewandowsky, J. C. Dunn, \& K. Kirsner (Eds.) Implicit memory: Theoretical issues, (pp. 47-65). Hillsdale, NJ: Erlbaum.

Schacter, D. L., \& Tulving, E. (1994). What are the memory systems of 1994?. In D. L. Schacter \& E. Tulving (Eds.), Memory systems 1994 (pp. 1-38). Cambridge, MA: MIT Press.

Schott, B. H., Wüstenberg, T., Wimber, M., Fenker, D.B., Zierhut, K. C., Seidenbecher, C. I., Heinze, H. J., Walter, H., Düzel, E., \& Richardson-Klavehn, A. (2013). The relationship between level of processing and hippocampal-cortical functional connectivity during episodic memory formation in humans. Human Brain Mapping, $34,407-424$.

Scoville, W. B., \& Milner, B. (1957). Loss of recent memory after bilateral hippocampal lesions. Journal of Neurology, Neurosurgery, \& Psychiatry 20, 11-21.

Slotnick, S. D. (2004). Visual memory and visual perception recruit common neural substrates. Behavioral \& Cognitive Neuroscience Reviews, 3, 207-221.

Sherry, D. F., \& Schacter, D. L. (1987). The evolution of multiple memory systems. Psychological Review, 94, 439-454.

Slotnick, S. D., \& Schacter, D. L. (2006). The nature of memory related activity in early visual areas. Neuropsychologia 44, 2874-2886.

Squire, L. R. (2004). Memory systems of the brain: A brief history and current perspective. Neurobiology of Learning \& Memory, 82, 171-177. 
Squire, L. R. (2009). Memory and brain systems: 1969-2009. Journal of Neuroscience, 29, $12711-12716$.

Squire, L. R., Dede, A. J., (2015). Conscious and unconscious memory systems. Cold Spring Harbor. Perspectives in Biology, 7 (3) (a021667).

Squire, L. R., \& Frambach, M. (1990). Cognitive skill learning in amnesia. Psychobiology, $18,109-117$.

Srinivas, K., \& Roediger, H.L. (1990). Classifying implicit memory tests: Category association and anagram solution. Journal of Memory \& Language, 29, 389-412.

Sternberg, G. (2006). Conceptual and perceptual factors in the picture superiority effect. European Journal of Cognitive Psychology, 18, 813-847.

Tenpenny, P. L., \& Shoben, E. J. (1992). Component processes and the utility of the conceptually-driven/data-driven distinction. Journal of Experimental Psychology: Learning, Memory \& Cognition, 18, 25-42.

Tulving, E., Kapur, S., Craik, F. I. M., Markowitsch, H. J., \& Houle, S. (1994).

Hemispheric encoding and retrieval asymmetry in episodic memory: Positron emission tomography findings. Proceedings of the National Academy of Sciences, USA, 91, 2016-2020.

Tulving, E., \& Schacter, D. L. (1990). Priming and human memory systems. Science, 247, 301-306.

Vaidya, C. J., Gabrieli, J. D. E., Keane, M. M., Monti, L. A., Gutierrez-Rivas, H., \& Zarella, M. M. (1997). Evidence for mulitple mechanisms of conceptual priming on implicit memory tests. Journal of Experimental Psychology: Learning, Memory \& Cognition, 23, 1324-1343. 
Visser, M., \& Lambon Ralph, M. A. (2011). Differential contributions of bilateral ventral anterior temporal lobe and left anterior superior temporal gyrus to semantic processes. Journal of Cognitive Neuroscience, 23, 3121-3131.

Voss, J. L., \& Paller, K. A. (2008). Brain substrates of implicit and explicit memory: The importance of concurrently acquired neural signals of both memory types. Neuropsychologia, 46, 3021-3029.

Voss, J. L., Federmeier, K. D., \& Paller, K. A. (2012). The potato chip really does look like Elvis! neural hallmarks of conceptual processing associated with finding novel shapes subjectively meaningful. Cerebral Cortex, 22, 2354-2364.

Wagner, A. D., Maril, A., Bjork, R. A., \& Schacter, D. L. (2001). Prefrontal contributions to executive control: fMRI evidence for functional distinctions within lateral Prefrontal cortex. Neuroimage, 14, 1337-1347.

Wagner A. D., Shannon B. J., Kahn I., \& Buckner R. L. (2005). Parietal lobe contributions to episodic memory retrieval. Trends in Cognitive Sciences 9, 445-453.

Ward, E. J., Chun, M. M., \& Kuhl, B. A. (2013). Repetition suppression and multi-voxel pattern similarity differentially track implicit and explicit visual memory. Journal of Neuroscience, 33, 14749-14757.

Wei, T., Liang, X., He, Y., Zang, Y., Han, Z., Caramazza, A., Bi, Y., 2012. Predicting conceptual processing capacity from spontaneous neuronal activity of the left middle temporal gyrus. Journal of Neuroscience, 32, 481-489.

Weiskrantz, L., \& Warrington, E. K. (1979). Conditioning in amnesic patients. Neuropsychologia, 17, 187-194.

Wiggs, C. L., Weisberg, J. \& Martin, A. (2006). Repetition priming across the adult lifespan - the long and short of it. Aging, Neuropsychology, and Cognition: A Journal on Normal and Dysfunctional Development, 13, 308-325. 
Weldon, M.S., Roediger, H.L., Beitel, D.A., \& Johnston, T.R. (1995). Perceptual and conceptual processes in implicit and explicit tests with picture fragment and word fragment cues. Journal of Memory \& Language, 34, 268-285.

Yaggie, M., Stevens, L., Miller, S., Abbott, A., Woodruff, C., Getchis, M., Stevens, S., Sherlin, L., Keller, B., \& Daiss, S. (2015). Electroencephalography coherence, memory vividness, and emotional valence effects of bilateral eye movements during unpleasant memory recall and subsequent free association: Implications for eye movement desensitization and reprocessing. Journal of EMDR Practice and Research, 9, 78-97. doi:10.1891/1933-3196.9.2.78 


\section{Footnotes}

1. The distinction between perceptual and conceptual processing is not the only processing based account of memory. Another explanation, relates to the distinction between activation and elaboration (e.g., Graf \& Mandler 1984; Mandler, Graf, \& Kraft, 1986). Within this, implicit tests of memory require activation whilst explicit tests are considered to be dependent upon elaboration. This account is not developed upon further here due to the focus on perceptual (vs. conceptual) processing.

2. The distinction between intentional and incidental memory in this experiment refers to the retrieval orientation of the subject during testing. The same terms can also be applied to encoding and the difference between intentional and incidental learning. Intentional learning refers to encoding situations where the goal of the subject is to memorise the study material. Incidental learning refers to the learning of material that results as a by-product of some other task (e.g., as through the use of a standard levels-of processing manipulation (e.g., Craik \& Tulving, 1975). Thus far, this distinction has received little attention in the SIRE literature in terms of direct manipulations of the encoding tasks. However, eye-movement influences have been found in separate studies in which encoding was either intentional (e.g., Christman et al., 2003; Lyle, Hanaver-Torrez, Hackländer, \& Edlin, 2012; Parker et al., 2008) or incidental (e..g., Christman, et al., 2006; Lyle, \& Jacobs, 2010; Parker \& Dagnall, 2010). More recently, Christman and Butler (2011) found encoding orientation (intentional vs. incidental) to have little effect so long as the material was processed to a conceptual level. However, this study did not manipulate eye-movements and considered only the effects of handedness. Consequently, this matter is something for future research. 
3. The reason why only strongly right-handed subjects were used in this experiment is that SIRE effects have been most consistently observed in strongly right-handed persons. An explanation for this is based on the hypothesis that handedness is related to differences in baseline levels of hemispheric interaction. Particularly, right-handed (vs. mixed-handed) individuals are claimed to have lower baseline levels of interactivity. Consequently, right-handed persons have more latitude to benefit from momentary boosts in interaction brought about by saccadic eye movements (Lyle et al., 2008). As such, and similar to other work (e.g., Nieuwenhuis, et al., 2013; Parker et al., 2017), only strongly right-handed individuals were used as participants in this experiment. 
TABLE 1

Mean proportion (and SD) of scores as a function of eye condition, test type and item type.

Eye Condition

\begin{tabular}{lll} 
& & \\
\cline { 2 - 3 } $\begin{array}{l}\text { Test Type } \\
\text { \& Item Type }\end{array}$ & Horizontal & \\
\hline & & \\
Conceptual Explicit & & $.19(.09)$ \\
Studied & $.31(.10)$ & $.06(.07)$ \\
Unstudied & $.07(.06)$ & \\
& & $.26(.11)$ \\
Conceptual Implicit & $.27(.11)$ & $.14(.07)$ \\
Studied & $.16(.09)$ & $.13(.11)$ \\
Unstudied & $.11(.13)$ & $.47(.10)$ \\
Priming & & $.13(.09)$ \\
Perceptual Explicit & $.51(.15)$ & \\
Studied & $.16(.12)$ & $.49(.14)$ \\
Unstudied & & $.30(.14)$ \\
Perceptual Implicit & $.51(.13)$ & \\
Studied & $.28(.13)$ & \\
Unstudied & $.23(.09)$ & \\
Priming & & \\
& & \\
\hline
\end{tabular}

